Fakultas Ekonomi, Universitas Cokroaminoto Yogyakarta

\title{
Dampak Kualitas Layanan dan Persepsi Harga Terhadap Kepuasan dan Loyalitas serta Peran Moderasi Gender (Studi Kasus Pada Nasabah Bank BRI di Yogyakarta) \\ Rinaldi
}

Prodi Manajemen, Fakultas Ekonomi, Universitas Cokroaminoto Yogyakarta

rinaldi@ucy.ac.id

\begin{abstract}
ABSTRAK
The purpose of this study is to determine and explain the effect of service quality on customer satisfaction (customer satisfaction); to determine and explain the effect of price perception on customer satisfaction (customer satisfaction); to determine and explain the effect of customer satisfaction (customer satisfaction) on customer loyalty (customer loyalty) and to determine and explain the effect of customer satisfaction (customer satisfaction) on customer loyalty (customer loyalty) moderated by gender. The sampling method that will be used is the non-probability sampling method. In this study, samples were obtained that were not planned, but by chance, which were available to researchers at the time of data collection (convenience sampling). The number of samples specified in the study was 300 people, this has fulfilled the assumption of using SEM and the limitations of time and cost. The sample in this study is BRI Bank customers in Yogyakarta. Analysis tool using SEM analysis with AMOS program. The results showed that service quality had an effect on customer satisfaction (customer satisfaction); price perception has an effect on customer satisfaction (customer satisfaction); customer satisfaction affects customer loyalty and gender affects the relationship between customer satisfaction and customer loyalty.
\end{abstract}

Keywords: service quality and price perception on satisfaction and loyalty

\begin{abstract}
ABSTRAK
Tujuan dari penelitian ini adalah untuk mengetahui dan menjelaskan pengaruh kualitas layanan terhadap kepuasan pelanggan; untuk mengetahui dan menjelaskan pengaruh persepsi harga terhadap kepuasan pelanggan; untuk mengetahui dan menjelaskan pengaruh kepuasan pelanggan terhadap loyalitas pelanggan serta untuk mengetahui dan menjelaskan pengaruh kepuasan pelanggan terhadap loyalitas pelanggan yang dimoderasi oleh gender. Metode pengambilan sampel yang akan digunakan dengan metode non-probability sampling. Dalam penelitian ini dapat diperoleh sampel yang tidak direncanakan, melainkan secara kebetulan yaitu subjek tersedia bagi peneliti pada saat pengumpulan data dilakukan (convenience sampling). Jumlah sampel yang ditentukan dalam penelitian ini sebanyak 300 orang, hal ini telah memenuhi asumsi penggunaan SEM dan dikarenakan keterbatasan waktu dan biaya. Sampel dalam penelitian ini adalah nasabah Bank BRI di Yogyakarta. Alat analisis dengan menggunakan analisis SEM dengan program AMOS. Hasil penelitian menunjukkan bahwa kualitas layanan (perceived service quality) berpengaruh terdahap kepuasan pelanggan (customer satisfaction); persepsi harga berpengaruh terdahap kepuasan pelanggan (customer satisfaction); kepuasan pelanggan (customer satisfaction) berpengaruh terhadap loyalitas pelanggan (customer loyalty) serta gender berpengaruh terhadap hubungan kepuasan pelanggan (customer satisfaction) dan loyalitas pelanggan (customer loyalty).
\end{abstract}

Kata Kunci: kualitas layanan dan persepsi harga terhadap kepuasan dan loyalitas 
Fakultas Ekonomi, Universitas Cokroaminoto Yogyakarta

\section{PENDAHULUAN}

Loyalitas pelanggan sangat penting artinya bagi perusahaan yang menjaga kelangsungan usahanya. Pelanggan yang setia adalah mereka yang sangat puas dengan produk dan pelayanan tertentu, sehingga mempunyai antusiasme untuk memperkenalkannya kepada siapapun yang mereka kenal. Selanjutnya pelanggan yang loyal tersebut akan memperluas kesetiaan mereka pada produk atau jasa buatan produsen yang sama. Seperti yang dikemukakan Kotler (2001) bahwa loyalitas tinggi adalah pelanggan yang melakukan pembelian dengan persentase semakin meningkat pada perusahaan tertentu daripada perusahaan lain. Loyalitas pelanggan adalah kondisi dimana pelanggan mempunyai sikap positif terhadap sebuah produk, mempunyai komitmen terhadap produk tersebut dan bermaksud melakukan pembelian ulang di masa yang akan datang. Lebih jauh, kehilangan pelanggan secara terus menerus akan menyebabkan suatu perusahaan menjadi pailit (Kotler dan Keller, 2007).

Oleh karena itu, perusahaan harus tetap menjaga dan mempertahankan para pelanggannya dengan cara meningkatkan loyalitas. Langkah yang ditempuh untuk mempertahankan loyalitas pelanggan dengan memberikan prioritas yang lebih besar pada pelanggan lama dibandingkan prioritas untuk mendapatkan pelanggan baru. Oleh karena itu, loyalitas pelanggan berdasarkan kepuasan murni dan terus-menerus merupakan salah satu aset terbesar yang mungkin didapat oleh perusahaan.

Meraih loyalitas pelanggan melalui kepuasan pelanggan bukan hal yang mudah. Kepuasan pelanggan merupakan faktor yang sangat penting bagi keberadaan, kelangsungan, dan perkembangan perusahaan. Menurut Engel, et al., (1990) kepuasan pelanggan merupakan evaluasi purnabeli dimana sekurangkurangnya memberikan hasil (outcome) sama atau melampaui harapan pelanggan. Sedangkan ketidakpuasan timbul apabila hasil yang diperoleh tidak memenuhi harapan pelanggan. Kepuasan merupakan fungsi dari persepsi atau kesan atas kinerja dan harapan, pelanggan puas dan jika kinerja melebihi harapan pelanggan, maka mereka akan merasa puas dan senang. Pelanggan yang puas terhadap barang dan jasa, kemungkinan besar akan membeli ulang dari penyedia 
Fakultas Ekonomi, Universitas Cokroaminoto Yogyakarta

barang dan jasa tersebut. Dengan demikian, perusahaan yang mampu memuaskan pelanggan akan dapat meningkatkan keuntungan dan pangsa pasarnya karena ada pembelian ulang dari pelanggan.

Kualitas pelayanan merupakan faktor penting yang harus diperhatikan perusahaan untuk mendapatkan loyalitas pelanggan. Goeth dan Davis (1994) mendefinisikan kualitas pelayanan merupakan suatu kondisi dinamis yang berhubungan dengan produk jasa, manusia, proses dan lingkungan yang mampu memenuhi dan atau melebihi harapan konsumen. Kualitas pelayanan dipengaruhi oleh harapan, kualitas proses dan output yang berkualitas. Pelayanan yang baik dapat dijadikan sebagai modal untuk menarik minat konsumen (Tjiptono,2002). Bagi perusahaan jasa tentu cukup sulit untuk mendapatkan standar pelayanan yang sama di mata konsumen. Hal ini menuntut kejelian pengelolaan SDM yang dimiliki agar kinerjanya optimum dalam memuaskan konsumen (Lupiyoadi, 2006). Oleh karena itu pelayanan yang baik dapat dijadikan modal untuk menarik minat konsumen karena kualitas pelayanan dapat menentukan kepuasan dan keinginan menggunakan lagi jasa tersebut. Pernyataan tersebut sesuai dengan penelitian yang dilakukan Elistia (2009), yang mengatakan bahwa kualitas pelayanan yang baik memiliki pengaruh positif terhadap loyalitas pelanggan.

Selain kualitas pelayanan, Persepsi harga juga merupakan faktor penting yang harus diperhatikan oleh perusahaan jasa. Harga adalah jumlah uang (kemungkinan ditimbang beberapa barang) yang dibutuhkan untuk memperoleh beberapa kombinasi sebuah produk dan pelayanan yang menyertainya (Kotler dan Keller, 2012). Sedangkan perpsepsi menurut Schiffman \& Kanuk (2000) adalah suatu proses dari seorang individu dalam menyeleksi, mengorganisasikan, dan menterjemahkan stimulus-stimulus atau informasi yang datang menjadi suatu gambaran yang menyeluruh.

Hasil penelitian Aga dan Safakli (2007) menunjukkan bahwa kualitas layanan dan persepsi harga memiliki dampak yang cukup signifikan terhadap kepuasan pelanggan. Hasil kajian literatur Dapkevicius dan Melnikas (2009) menemukan bukti empiris bahwa kualitas layanan dan persepsi harga memiliki dampak terhadap kepuasan pelanggan. Menurut Blattebert dan Deighton (1996) “ adalah lebih mudah untuk mendapatkan current customer daripada untuk mendapatkan seorang customer baru, ini berarti bahwa 
Fakultas Ekonomi, Universitas Cokroaminoto Yogyakarta

perusahaan lebih mudah mempertahankan current customer, karena telah kenal dan mengetahui serta telah mengevaluasi kinerja produk atau jasa perusahaan. Perusahaan harus mempelajari apa yang menjadi kebutuhan dan apa yang diinginkan pelanggan dengan mengetahui faktor-faktor yang dapat mempengaruhi seorang pelanggan secara individu seperti produk apa yang diinginkan oleh pelanggan, gender, kelas sosial, dan gaya hidup (Sutisna, 2001).

Menurut Kotler dan Keller (2009), kebutuhan dan keinginan pelanggan sangat berhubungan dengan jenis kelamin atau gender. Hasil penelitian Sumarwan (2002) menunjukkan bahwa kepuasan pelanggan laki-laki dan perempuan dalam mencapai loyalitas pelanggan tentunya memiliki suatu perbedaan karena setiap individu pelanggan memiliki sudut pandang yang berbeda-beda, sehingga mempengaruhi perilaku dan tanggapan yang berbeda akan suatu produk. Menurut Paul (2007), bahwa gender berpengaruh positif dan signifikan dengan loyalitas pelanggan yang menyebabkan terbentuknya motivasi untuk membeli kembali. Beberapa penelitian mengatakan bahwa gender sebagai moderasi, dimana gender dapat mempengaruhi baik memperkuat maupun memperlemah pengaruh antar variabel yang diteliti (Kirana dan Yasa, 2013).

\section{TINJAUAN PUSTAKA}

\section{Pengaruh Kualitas Layanan terdahap kepuasan pelanggan (Customer Satisfaction)}

Model kualitas layanan mendapatkan banyak perhatian setelah temuan kontroversial Parasuraman et al pada tahun 1985. Model ini memandang kualitas layanan sebagai diferensiasi perbandingan antara persepsi dan harapan konsumen akan layanan dan kinerja aktual dari layanan yang diterima oleh konsumen yang disediakan oleh perusahaan pada periode waktu tertentu (Parasuraman et al, 1985).

Hasil penelitian Hidayat (2009) menunjukkan bahwa kualitas layanan berpengaruh positif dan signifikan terhadap kepuasan nasabah. Hasil studi ini juga membuktikan bahwa kajian teoritis dan studi empirik yang menyatakan dan menyebutkan adanya pengaruh yang positif dan signifikan antara kualitas layanan dan kepuasan nasabah juga dapat digunakan untuk studi dibidang perbankan di Indonesia khususnya Bank Mandiri Jawa Timur. Hasil penelitian (Khatibi et al., 2002) menunjukan bahwa terdapat pengaruh yang positif antara 
kualitas layanan berpengaruh terhadap kepuasan pelanggan. Kualitas pelayanan harus menjadi fokus utama perhatian perusahaan. Persaingan yang sangat ketat, dengan semakin banyak produsen yang terlibat dalam pemenuhan kebutuhan dan keinginan konsumen menyebabkan setiap perusahaan harus mampu menempatkan orientasi pada kepuasan pelanggan sebagai tujuan utama. pada dasarnya tujuan sebuah bisnis adalah menciptakan para pelanggan yang puas.

$\mathrm{H}_{1}$ Kualitas layanan (Perceived Service Quality) berpengaruh terdahap kepuasan pelanggan (Customer Satisfaction).

\section{Pengaruh Persepsi Harga terdahap kepuasan pelanggan (Customer Satisfaction)}

Persepsi harga juga merupakan faktor penting yang harus diperhatikan oleh perusahaan jasa. Harga adalah jumlah uang (kemungkinan ditimbang beberapa barang) yang dibutuhkan untuk memperoleh beberapa kombinasi sebuah produk dan pelayanan yang menyertainya (Kotler dan Keller, 2012). Sedangkan perpsepsi menurut Schiffman \& Kanuk (2000) adalah suatu proses dari seorang individu dalam menyeleksi, mengorganisasikan, dan menterjemahkan stimulus-stimulus atau informasi yang datang menjadi suatu gambaran yang menyeluruh. Penelitian Zhang (2001) menunjukan bahwa terdapat pengaruh yang positif antara persepsi harga berpengaruh terhadap kepuasan pelanggan. Persaingan membuat dunia usaha berusaha untuk memuaskan kebutuhan pelanggan dengan harga yang rendah.

$\mathrm{H}_{2}$ Persepsi harga berpengaruh terhadap kepuasan pelanggan (Customer Satisfaction).

Pengaruh Kepuasan Pelanggan (Customer satisfaction) terhadap Loyalitas Pelanggan (Customer Loyalty).

Menurut Kotler (2002), pengertian kepuasan pelanggan mangacu kepada dua variable, yaitu jasa yang dirasakan (perceived service) dan jasa yang diharapkan (expected service) oleh pelanggan. Dikatakan puas apabila jasa yang mereka rasakan melebihi apa yang mereka harapkan. Sementara ketidak puasan akan menjadi manakala pelanggan merasakan sesuatu yang kurang daripada yang mereka harapkan.mengacu dari dua variable tersebut Kotler (2002) mendefinisikan kepuasan pelanggan sebagai berikut; perasaan 

kesannya terhadap kinerja (atau hasil) suatu produk dan harapan-harapnya. Mencapai tingkat kepuasan pelanggan yang maksimal adalah tujuan utama pemasaran.Ketika pelanggan merasa puas atas pelayanan yang didapatkan, maka besar kemungkinan mereka akan kembali lagi untuk melakukan pembelian selanjutnya dan mereka akan merekomendasikan pada teman - teman dan orang disekitar tentang perusahaan tersebut. Pemasaran bukan hanya sekedar melakukan penjualan saja, tapi bagai mana memuaskan pelanggan terus-menerus agar mereka bertahan.

$\mathrm{H}_{3}$ : Kepuasan pelanggan (Customer Satisfaction) berpengaruh terhadap loyalitas pelanggan (Customer Loyalty).

\section{Gender (Jenis Kelamin)}

Perusahaan harus mempelajari apa yang menjadi kebutuhan dan apa yang diinginkan pelanggan dengan mengetahui faktor-faktor yang dapat mempengaruhi seorang pelanggan secara individu seperti produk apa yang diinginkan oleh pelanggan, gender, kelas sosial, dan gaya hidup (Sutisna, 2001). Menurut Haryono dan Hastjarjo (2010) gender merupakan variabel demografi yang didefinisikan sebagai cara pandang yang berbeda terhadap suatu produk, perbedaan gender sebagai bagian dari demografi dapat memoderasi perilaku konsumen. Hal tersebut juga diunggkapkan dalam penelitian yang dilakukan Guiry et al (2006) menyatakan adanya perbedaan perilaku pembelian yang dipengaruhi oleh karakteristik demografi dan sosial ekonomi.

$\mathrm{H}_{4}$ : Gender berpengaruh terhadap hubungan kepuasan pelanggan (Customer Satisfaction) dan loyalitas pelanggan (Customer Loyalty).

\section{METODE PENELITIAN}

Jenis penelitian yang dilakukan adalah penelitian survei, yaitu pengumpulan informasi secara sistematik dari para responden dengan maksud untuk memahami dan atau meramalkan beberapa aspek perilaku dari populasi yang diamati. Penelitian survei pada umumnya dilakukan untuk mengambil suatu generalisasi dari pengamatan yang tidak 
Fakultas Ekonomi, Universitas Cokroaminoto Yogyakarta

mendalam (Sugiyono, 2010). Populasi adalah jumlah dari keseluruhan obyek yang akan diteliti. Dalam penelitian ini populasi yang digunakan adalah nasabah BRI di Yogyakarta.

Adapun sampel adalah sebagian populasi yang diambil atau ditentukan berdasarkan karakteristik tertentu dan dianggap dapat mewakili keseluruhan populasi. Selanjutnya, Sugiyono (2010) mengatakan bahwa sampel adalah bagian dari populasi. Sampel merupakan bagian populasi yang terwakili dan akan diteliti atau sebagian jumlah dari karakteristik yang dimiliki oleh populasi yang terwakili. Metode pengambilan sampel yang akan digunakan dalam penelitian ini adalah metode non-probability sampling, karena jumlah anggota populasinya tidak diketahui secara rinci. Dalam penelitian ini dapat diperoleh sampel yang tidak direncanakan, melainkan secara kebetulan yaitu subjek tersedia bagi peneliti pada saat pengumpulan data dilakukan (convenience sampling). Jumlah sampel yang ditentukan dalam penelitian ini sebanyak 300 orang, hal ini telah memenuhi asumsi penggunaan SEM dan dikarenakan keterbatasan waktu dan biaya. Didalam menganalisis digunakan metode analisis yang digunakan adalah Structural Eqation Modelling (SEM). Structur Equation Modeling (SEM) AMOS.

\section{HASIL PENELITIAN DAN PEMBAHASAN}

Penelitian ini data diperoleh melalui penyebaran daftar pertanyaan (kuisioner) kepada 300 responden yaitu Nasabah BRI di Yogyakarta. Metode analisis data yang digunakan dalam penelitian ini adalah analisis deskriptif yang meliputi penggambaran karakteristik responden yang menjadi sampel penelitian dan deskripsi data penelitian serta analisis kuantitatif dengan analisis SEM dengan program AMOS. Evaluasi terhadap model multifaktor dari pengukuran di atas menghasilkan indeks-indeks goodness of fit sebagaimana disajikan pada tabel berikut: 
Fakultas Ekonomi, Universitas Cokroaminoto Yogyakarta

Tabel 1

Hasil Goodness of Fit Model Pengukuran

\begin{tabular}{|l|c|c|c|}
\hline \multicolumn{1}{|c|}{ Index } & $\begin{array}{c}\text { Cut off } \\
\text { Value }\end{array}$ & Hasil & $\begin{array}{c}\text { Evaluasi } \\
\text { Model }\end{array}$ \\
\hline Chi-Square & & 16,137 & \\
\hline Probabilitas & $\geq 0,05$ &, 109 & Baik \\
\hline CMIN/DF & $\leq 2,00$ & 1,077 & Baik \\
\hline GFI & $\geq 0,90$ & 0,904 & Baik \\
\hline AGFI & $\geq 0,90$ & 0,915 & Baik \\
\hline TLI & $\geq 0,95$ & 0,950 & Baik \\
\hline CFI & $\geq 0,95$ & 0,958 & Baik \\
\hline RMSEA & $\leq 0,08$ & 0,013 & Baik \\
\hline
\end{tabular}

Sumber : Hasil olah data

Indeks-indeks goodness of fit model pengukuran (measurement model) pada Tabel di atas menunjukkan hasil yang baik, sehingga model yang ada telah memberikan estimasi model yang fit dan dapat menjadi model struktural penuh pada model awal tersebut. Hipotesis yang merepresentasikan pengaruh suatu konstruk terhadap konstruk lain diuji dengan memeriksa apakah koefisien path (standardized estimate) yang menghubungkan kedua konstruk tersebut signifikan pada taraf signifikansi $\alpha=0,05$. Rangkuman hasil pengujian hipotesis bisa dilihat pada tabel berikut ini. 
Tabel 2.

Hasil Uji Hipotesis

\begin{tabular}{|c|c|c|c|c|c|}
\hline Hipotesis & Path Hubungan & $\begin{array}{c}\text { Standardized } \\
\text { Estimated }\end{array}$ & C.R & $\mathbf{P}$ & Keterangan \\
\hline $\mathrm{H} 1$ & $\begin{array}{l}\text { Kualitas Layanan } \rightarrow \\
\text { Kepuasan }\end{array}$ & 0,035 & 2,714 & 0,007 & Terbukti \\
\hline $\mathrm{H} 2$ & $\begin{array}{l}\text { Persepsi Harga } \rightarrow \\
\text { Kepuasan }\end{array}$ & 0,046 & 17,508 & 0,000 & Terbukti \\
\hline $\mathrm{H} 3$ & $\begin{array}{l}\text { Kepuasan } \rightarrow \\
\text { Loyalitas }\end{array}$ & 0,072 & 4,619 & 0,000 & Terbukti \\
\hline $\mathrm{H} 4$ & $\begin{array}{l}\text { Moderasi } \rightarrow \\
\text { Loyalitas }\end{array}$ & 0,018 & 2,790 & 0,033 & Terbukti \\
\hline
\end{tabular}

* signifikan pada level 0,05.

a. Pengujian hipotesis pertama

Hasil estimasi Kualitas layanan (Perceived Service Quality) berpengaruh terdahap kepuasan pelanggan (Customer Satisfaction) diperoleh koefisien path (standardized estimate) sebesar 0,035. Uji signifikansi koefisien ini diperoleh nilai C.R sebesar 2,714. Nilai probabilitas signifikansi sebesar 0,007 maka hipotesis pada taraf signifikan 5\% diterima, yang berarti Kualitas layanan (Perceived Service Quality) berpengaruh terdahap kepuasan pelanggan (Customer Satisfaction). Dengan demikian hipotesis 1 yang menyatakan bahwa Kualitas layanan (Perceived Service Quality) berpengaruh terdahap kepuasan pelanggan (Customer Satisfaction) terbukti. Hal ini berarti makin tingginya kualitas layanan menjadikan tingginya kepuasan pelanggan. Kualitas pelayanan merupakan kunci untuk mencapai kesuksesan. Baik tidaknya kualitas pelayanan barang atau jasa tergantung pada kemampuan produsen dalam memenuhi harapan pelanggan secara konsisten. Kualitas pelayanan dikatakan memuaskan jika layanan yang dirasakan sama atau melebihi kualitas layanan yang diharapkan. Pelayanan yang seperti inilah yang dipersepsikan sebagai pelayanan berkualitas dan ideal. Harapan pelanggan tersebut tercermin pada dimensi kualitas 
Fakultas Ekonomi, Universitas Cokroaminoto Yogyakarta

pelayanan seperti tangibles (bukti fisik), reliability (keandalan), responsiveness (daya tanggap), assurance (jaminan), dan empathy (empati). Pelayanan yang baik, ramah tamah, sopan santun, ketepatan waktu, dan kecepatan dalam pengiriman barang menjadi nilai penting yang diharapkan oleh para pelanggan. Oleh karena itu, kualitas pelayanan harus menjadi fokus utama perhatian perusahaan karena dapat menciptakan kepuasan pelanggan (Bei dan Chiao, 2001).

b. Pengujian hipotesis kedua

Hasil estimasi Persepsi harga berpengaruh terdahap kepuasan pelanggan (Customer Satisfaction) diperoleh koefisien path (standardized estimate) sebesar 0,046. Uji signifikansi koefisien ini diperoleh nilai C.R sebesar 17,508. Nilai probabilitas signifikansi sebesar 0,000 maka hipotesis pada taraf signifikan 5\% diterima, yang berarti Persepsi harga berpengaruh terdahap kepuasan pelanggan (Customer Satisfaction). Dengan demikian hipotesis 2 yang menyatakan bahwa Persepsi harga berpengaruh terdahap kepuasan pelanggan (Customer Satisfaction) terbukti. Hal ini berarti makin baiknya persepsi harga menjadikan tingginya kepuasan pelanggan. Persepsi harga juga merupakan faktor penting yang harus diperhatikan oleh perusahaan jasa. Harga adalah jumlah uang (kemungkinan ditimbang beberapa barang) yang dibutuhkan untuk memperoleh beberapa kombinasi sebuah produk dan pelayanan yang menyertainya (Kotler dan Keller, 2012).

c. Pengujian hipotesis ketiga

Hasil estimasi Kepuasan pelanggan (Customer Satisfaction) berpengaruh terhadap loyalitas pelanggan (Customer Loyalty) diperoleh koefisien path (standardized estimate) sebesar 0,072. Uji signifikansi koefisien ini diperoleh nilai C.R sebesar 4,619. Nilai probabilitas signifikansi sebesar 0,000 maka hipotesis pada taraf signifikan 5\% diterima, yang berarti Kepuasan pelanggan (Customer Satisfaction) berpengaruh terhadap loyalitas pelanggan (Customer Loyalty). Dengan demikian hipotesis 3 yang menyatakan bahwa Kepuasan pelanggan (Customer Satisfaction) berpengaruh terhadap loyalitas pelanggan (Customer Loyalty terbukti. Hal ini berarti makin tingginya Kepuasan pelanggan (Customer Satisfaction) 
Fakultas Ekonomi, Universitas Cokroaminoto Yogyakarta menjadikan tingginya loyalitas pelanggan (Customer Loyalty). Mencapai tingkat kepuasan pelanggan yang maksimal adalah tujuan utama pemasaran. Ketika pelanggan merasa puas atas pelayanan yang didapatkan, maka besar kemungkinan mereka akan kembali lagi untuk melakukan pembelian - pembelian selanjutnya dan mereka akan merekomndasikan pada teman-teman dan orang disekitar tentang perusahhan tersebut. Pemasaran bukan hanya sekedar melakukan penjualan saja, tapi bagai mana memuaskan pelanggan terus-menerus agar mereka bertahan.

\section{d. Pengujian hipotesis keempat}

Hasil estimasi Gender berpengaruh terhadap hubungan kepuasan pelanggan (Customer Satisfaction) dan loyalitas pelanggan (Customer Loyalty) diperoleh koefisien path (standardized estimate) sebesar 0,018. Uji signifikansi koefisien ini diperoleh nilai C.R sebesar 2,790. Nilai probabilitas signifikansi sebesar 0,033 maka hipotesis pada taraf signifikan 5\% diterima, yang berarti Gender berpengaruh terhadap hubungan kepuasan pelanggan (Customer Satisfaction) dan loyalitas pelanggan (Customer Loyalty). Dengan demikian hipotesis 4 yang menyatakan bahwa Gender berpengaruh terhadap hubungan kepuasan pelanggan (Customer Satisfaction) dan loyalitas pelanggan (Customer Loyalty) terbukti. Hal ini berarti perbedaan Gender akan memoderasi pengaruh kepuasan pelanggan (Customer Satisfaction) terhadap loyalitas pelanggan (Customer Loyalty). Hasil penelitian Sumarwan (2002) menunjukkan bahwa kepuasan pelanggan laki-laki dan perempuan dalam mencapai loyalitas pelanggan tentunya memiliki suatu perbedaan karena setiap individu pelanggan memiliki sudut pandang yang berbeda-beda, sehingga mempengaruhi perilaku dan tanggapan yang berbeda akan suatu produk.

\section{KESIMPULAN DAN SARAN}

Hasil penelitian menunjukkan bahwa kualitas layanan (perceived service quality) berpengaruh terdahap kepuasan pelanggan (customer satisfaction); persepsi harga berpengaruh terdahap kepuasan pelanggan (customer satisfaction); kepuasan pelanggan (customer satisfaction) berpengaruh terhadap loyalitas pelanggan (customer loyalty) serta gender berpengaruh terhadap hubungan kepuasan pelanggan (customer satisfaction) dan 


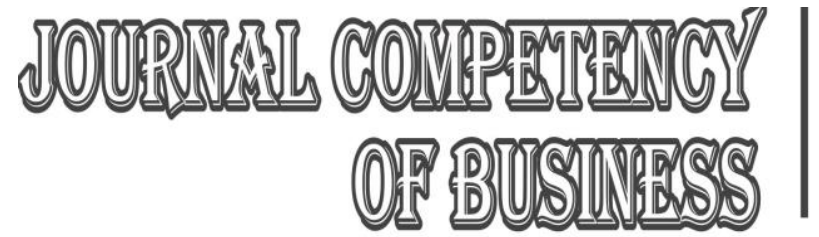

Fakultas Ekonomi, Universitas Cokroaminoto Yogyakarta loyalitas pelanggan (customer loyalty).

Mengingat konsumen mempunyai persepsi akan harga yang ditawarkan dan produk mampu mengisyaratkan akan pribadinya yang menyebabkan harga ini dapat berperan secara negatif dan positif. Kondisi demikian sebaiknya pemasar hati-hati dalam membuat kebijakan harga, seperti untuk penetapan harga produk termasuk pemberian diskon, kupon dan lain-lainnya, karena bisa-bisa konsumen menganggap produk tersebut sudah tidak baik lagi. Dengan demikian pada saat promosi dan memberikan diskon, obral, kupon dan voucher sebaiknya yang dapat memberikan peran positif. Misalnya pemberian diskon pada barang/produk yang sudah dianggap konsumen merupakan produk yang dipersepsikan eksklusif dan berkualitas di mata konsumen.

\section{DAFTAR PUSTAKA}

Aga, M. \& Safakli, O. V. 2007. An Empirical Investigation of Service Quality and Customer Satisfaction in Proffesional Accounting Firms : Evidence From North Cyprus. Journal of Problems and Perspective in Management. 5 (3)

Bei, Lien-Ti \& Chiao, Yu-Ching. 2001. An Empirical Study of Servqual's Dimensionality. The Service Industries Journal. 18 (2)

Blattbert, R.C dan Deighton, J. 1996. Manage Marketing By The Customer Equity Test, Harvard Business Review, July-August

Elistia, Muhammad Rizan. 2014. Pengaruh Citra Toko, Private Brand, dan Kualitas Pelayanan terhadap Kepuasan Pelanggan dan Loyalitas Pelanggan Supermarket Studi Kasus Pada 4 Supermarket Yaitu Carrefour, Giant, Alfa, Dan Superindo di Wilayah Jakarta Barat. Jurnal. Pascasarjana Magister Manajemen, Universitas INDONUSA Esa Unggul, Jakarta

Engel, Blackwell \& Miniard. 1990.Consumer Behavior. 8th . The Dryden Press, USA

Ferdinand, A., 2002, Structural Equation Modeling dalam Penelitian Manajemen, Edisi ke 2, BP UNDIP, Semarang

Goeth, D.L \& Davis, S. 1994. Introduction to Total Quality, Quality, Productivity, Competitiveness, Englewood Cliffs, NJ, Prentice Hall International Inc

Guiry, Michael. Magi, Anne W. and Lutz, Richard J. 2006. Defining and Measuring Recreational Shopper Identity. Journal of the Academy of Marketing Science, Vol. 34,No. 1 
Fakultas Ekonomi, Universitas Cokroaminoto Yogyakarta

Haryono, Tulus dan Hastjarjo, Dwi. 2010. Peran Gender, Pendapatan, dan Pendidikan Terhadap Loyalitas Konsumen yang Berkunjung ke Mall. Jurnal Kinerja, 14 (2)

Hidayat, Arwan. 2009. Analisis Pengaruh Kualitas Produk, Promosi dan Persepsi Harga Terhadap Minat Beli Ulang Pelanggan Voucher Isi Ulang XL di Universitas Semarang. Jurnal Akuntansi, Manajemen Bisnis dan Sektor Publik. Vol 7 No 1

Khatibi et al., 2002. The Impact of Price Perception, Service Quality, And Brand Image On Custumer Loyalty (Study Of Hospitality Industry In Pakistan Interdisciplinary, Journal Of Contempory Research In Business Vol 4, No. 5

Kirana, I Dewa Ayu Intan, dan Yasa, Ni Nyoman Kerti. 2013. Peran Gender dalam Memoderasi Pengaruh Perceived Benefit dan Perceived Cost Terhadap Niat Menggunakan Kartu Kredit di Kota Denpasar. Jurnal Ekonomi dan Bisnis, 2 (2)

Kotler, Philip. 2001. Manajemen Pemasaran. Edisi Kesepuluh. PT Indeks Kelompok Gramedia. Jakarta. Terjemahan AB Susanto , 2002. Manajemen Pemasaran, Jilid 1, Edisi Milenium, Jakarta. Prehallindo

Kotler, Philip dan Keller, Kevin. 2007. Manajemen Pemasaran, edisi ke-12, Jilid I, Jakarta. PT Indeks. Terjemahan Budijanto

Kotler, Philip dan Keller, Kevin. 2012. Marketing Management 14th edition. Jakarta:PT. Indeks Kelompok Gramedia

Lupiyoadi, Rambat. 2006. Manajemen Pemasaran Jasa. Jakarta : Salemba Empat

Parasuraman, A., Zeithalm, V., dan Berry L., 1985. Journal of Marketing: A Conceptual Model A of Service Quality and Its Implication for Future Research

Paul G. Patterson 2007. Demographic Correlates of Loyalty in a Service Context. Journal of Service Marketing, Scoll of Marketing

Schiffman, Leon G. dan Lesli Lazar Kanuk, 2000. Consumer Behavior, 7th Edition, Prentice Hall Inc, Upper Saddle River, New Jersey.

Sugiyono. 2010. Metode Penelitian Kuantitatif Kualitatif \& RND. Bandung : Alfabeta

Sumarwan, Ujang. 2002. Perilaku Konsumen: Teori dan Penerapannya dalam Pemasaran. Bandung: Penerbit Ghalia Indonesia

Sutisna. 2001. Perilaku Konsumen dan Komunikasi Pemasaran. PT. Remaja Rosdakarya, Bandung

Tjiptono, Fandy. 2002. Manajemen Jasa Edisi II Cetakan Ketiga. Yogyakarta : Andy

Zhang. 2001. The Effect of Brand Image and Traceability Certification on Consumer's Value Perceptions Mediating Role of Perceived Quality and Perceived Risk. Journal of Business an Industrial Marketing. Vol 5 